\title{
These Are Only Hints and Guesses
}

\author{
Francesca Torzo
}

Editorial Summary: In »These Are Only Hints and Guesses« Francesca Torzo explores experience, conscience, and culture as territories to reflect on architecture. Tracing back the narratives and stories from the past as a basic foundation of knowledge, she unravels the resonance of history and knowledge within contemporary experience and design in architecture. Based upon what has been, the thinking and making of architecture is always embedded in the stream of memory and tradition, referring to what was there before. Proceeding from this basis, the personal archive of memories fuels the processes of association and imagination. Any idea is integral to a cultural context, while culture is considered to be this stream of consciousness, forming the background to recent lived experience and its projection into future conception and design. [Uta Graff]

Keywords: Time; Spatial Relations; Memory; Vision; Allusions; Perception; Observation; Experience.

»Co, go, go, said the bird: human kind

Cannot bear very much reality.

Time past and time future

What might have been and what has been

Point to one end, which is always present."

T. S. Eliot: 1935.

»]'ai beaucoup reconstruit : c'est collaborer avec les temps sous son aspect de passé, en saisir ou en modifier l'esprit, lui server de relais vers un plus long avenir; c'est retrouver sous le pierres le secret des sources. Notre vie est brève : nous parlons sans cesse des siècles qui précèdent ou qui suivent le nôtre comme s'ils nous étaient totalement étrangers; j'y touchais pourtant dans mes jeux avec la pierre. Ces murs que j'étaie sont encore chauds du contact de corps disparus; des mains qui n'existent pas encore caresseront ces fut de colonnes."

Marguerite Yourcenar: 1958.

Corresponding author: Francesca Torzo (Bergen Architecture School, Bergen, Norway); mail@francescatorzo.it 


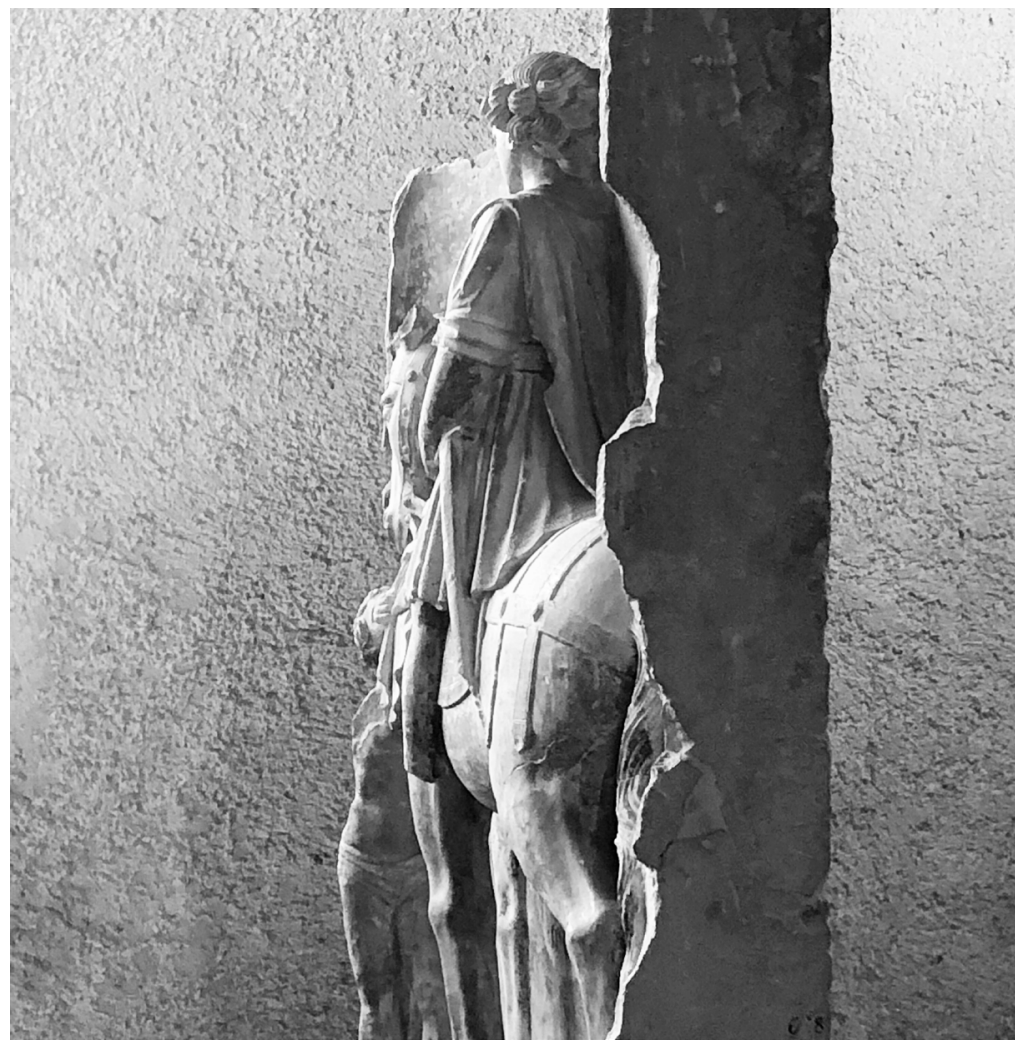

"Layering of Time, Presences and Sensations", Carlo Scarpa: Renovation and Addition of Castelvecchio, Verona, 1958-1964. Photographer: Francesca Torzo, 2020. 
At the age of eight, Heinrich Keller, son of a baker from Zurich, suffered a very serious leg fracture and was confined to bed for years. On the eve of the march on Versailles and the establishment of the first French Republic yet immobilized by his confinement, Heinrich began to draw landscapes that he had never visited, but imagined with precision and an abundance of detail. It was the year 1786, the time when Natural philosophers, namely the mathematicians, were divided in debates about Newton's laws, Northern European writers started to travel through Italy, and Count Gaspard Monge began his invention of descriptive geometry. It was during this time that the Paris Constituent Assembly voted for the meter - a submultiple of the Paris meridian - as the new unit of measurement. While the most skilled artisans migrated from city to city and country to country, crossing wars deploying makeshifts, as was the case of the peculiar journey from the Prussian Neuchatel through the courts of Madrid, Paris, London, and all the way to China for the invention of the first three mechanical dolls: the Writer, the Designer, and the Harpsichord Player.

As an apprentice for more than 20 years at Henri Füssli atelier and later at his own publishing shop - which he had opened at about the age of $40-$ Heinrich meticulously recreated the Swiss Alpine landscapes on cartographic maps and plates burnished by the candles' smoke, moving his gaze afar to Lake Maggiore and Milan. The topography of the Alps, the streets, the cities, the human artefacts, and the detailed scenes of daily life are portrayed like the characters of one unitary landscape, a fresco most probably just imagined by this unusual engraver who did not travel much but collected the tales of contemporary voyagers. The minimalism of his panoramas magnifies the details that inhabit the landscape, whether they entail a thickening of lines portraying a couple on a walk along a countryside path or small rural buildings up on a mountain pasture, Zurich bell towers or the outstretched profile of the Alps. The panoramas that Keller imagined, or reconstructed, depict landscapes that were formed with millenary slowness: the Alps' chains that have been inhabited by individuals and communities for centuries and the cities, and villages that are still part of everyday life.

When we look out of an airplane window today, we can observe the movements of the mountain chains and valleys and see how the roads, railways, and bridges were largely built with a pragmatic intelligence that reflects the topography. We can also see how the configuration of villages and cities changes, hinting at a memory of the topography. Similarly, when 
walking down the streets of historical cities, the flow of the roads and the arrangement of the facade walls express the memory of the first settlements, and we are able to sense if we are in a place formed by meandering rivers and sand, by the clash of the plates of Africa and Europe, or by the deposition of volcanic ashes. Cities and houses recount thousands of years of geology as well as how humans decided to settle in a landscape and how, over the centuries, the various communities made the decision to confirm, or transform, parts of these cities.

The transformation of cities, at least until after the First and Second World Wars, rarely contradicted the initial settlement decisions. Rather, they more often confirmed the pre-existing urban and architectural structures, building and evolving them, inhabiting them with new signifiers, and demolishing parts and adding others. This was likely a result of the slowness of the processes that made necessary and inevitable an economics of the act of building, in the sense of a wise »home administration «, aiming for a maximum result with a minimum expenditure of means. If the character, that is the cultural expression of the city, has been deeply transformed over time, seeing that construction is an instrument that represents culture and the communication - as well as the festivity - of the political power around which a community converges and finds agreement for a finite period of time. Nevertheless, it is possible to detect the permanence of a »cultural structure of cities, phrasing that attempts to name the ensemble of characteristics that has survived over centuries and that makes an anthropic location unique.

As architects, we are always confronted with an area that has already been inhabited, whether it is a landscape or an urban context. It is never a tabula rasa. The underlying question of our profession is perhaps how to successfully observe and recognize the »cultural structure« of a place, meaning those permanencies that cannot be ascribed to a language or a form, though they inevitably express the cultural cipher, as well as the technique and availability of the means and materials specific to a historical period that therefore cannot be reproduced, and consists of spatial relationships that are specific to each place. These relationships, between human constructions and a topography, as well as among the constructions themselves, are not parametric nor linguistic. Indeed these spatial relationships can be identified and measured, but they do not address univocally a set of ratios nor a deterministic parametric rule; they seem to be the result of building gestures 
being repeated over centuries, even with different phrasing, and they convey the idea and the perception of a place. The loggia, for example, is the expression of a Mediterranean life, not so much due to the figure of the loggia itself, but as a result of the culture of living that they allude to and dispose. If we visit a masonry loggia veiled with a thin layer of plaster, or a loggia built of wood or concrete, our mind recalls a memory, together with a vision, of the sun.

The question of »how do we know what we know « arises.

In his notes on painting, Leonardo da Vinci observed how difficult it was to paint the »concept in the mind of $m a n$ « because unlike the portrait of a man as a body, which can be easily parametrized, the »concept«, or the culture, must be drawn through gestures and movements; it is alive. Even buildings and cities are alive. They continue to live in the spaces that human beings are able to inhabit with new meaning.

It seems to me that the mind of people is »hungry«, it needs continuous nourishment and an imperceptible unaware swing between distraction and concentration. Our senses constantly recollect flakes of experience and store them in our mind; then, unpredictably though precisely, our mind recomposes these fragments into wholes, which orient our perception and our communication of the world. This continuous movement of associations and allusions is paradoxical. Somehow, we may find solace in imagining that our mind has space to host contradictions and store them, awaiting a time for them to become a new entity of perception, which may be a memory, a vision, or both.

Observing these human phenomena instils a kind of empathy for beings which soothes impatience. It does take patience and an open-minded curiosity to overcome one's own individuality and to be able to read the contradictory experiences of others' lives and cultures as well as to learn from them. The privilege of our profession is that it offers us the possibility of arranging spatial dispositions that reflect these experiences, thus belonging harmoniously to the slow phenomena of human culture that unravels far beyond the lifetime of a human being.

I interpret the architect's profession as a director of fiction, meant as a weaver of narratives at the disposal of people's experiences; hence, observing is an ineffable source of collecting experiences and imaginaries that belong to individuals as well as to a collective. We trace these narratives by stitching together the primary spatial relations, training a clarity in formulating 
questions, and then it is our responsibility to ensure that the promises are not compromised, so that people may live the authenticity of an experience, while we leave the scene.

Measures reveal and trace orders among living beings, things, spaces. I recall Vitruvius's enthusiasm in describing how the square and compass - in Latin straight lines, euthygrammi, and constellations, circini - were the utensils of geometry addressed as the mental tool in charge of tuning harmony of the parts with the whole.

Geometrical drawings are hence open maps which note the potential orders, rhythms, and harmonies of spaces. It seems that there is not one dimension better than another, nor a proportion more compelling than another. Dimensions do not have a value on their own but exist out of relations with other dimensions, and their meaning or scale perception changes throughout time. Therefore, the proportional systems investigated throughout centuries by mathematicians, philosophers, and architects resemble folk tales, beautiful ones, that express the everlasting human need to obtain the secret rule of the universe, and we find ourselves among contradictory theories that are equally true.

The main concern of my daily work is exactly this observation of the »cultural structure of a place and the search for consonance and decorum, which are not figurative, but rather an expressive morphology with the hope of weaving a cultural continuity that is able to include contrasts between those who lived before us and those who will come.

References

Eliot, Thomas Stearns (1935): »Burnt Norton«, in: Four Quartets, 1937-1942.
Yourcenar, Marguerite (1958): »Tellus Stabilita«, in: Marguerite Yourcenar, Mémoires d'Hadrien, Paris: Gallimard. 